\title{
Feasibility of a novel, synthetic, self- assembling peptide for suture-line haemostasis in cardiac surgery
}

\author{
Suresh Giritharan ${ }^{1,2^{*}}$, Kareem Salhiyyah ${ }^{1}$, Geoffrey M. Tsang ${ }^{1}$ and Sunil K. Ohri ${ }^{1}$
}

\begin{abstract}
Backgroud: To assess the feasibility and efficacy of PuraStat ${ }^{\oplus}$, a novel haemostatic agent, in achieving suture line haemostasis in a wide range of cardiac surgical procedures and surgery of the thoracic aorta.

Methods: A prospective, non-randomised study was conducted at our institution. Operative data on fifty consecutive patients undergoing cardiac surgery where PuraStat ${ }^{\circledR}$ was utilised in cases of intraoperative suture line bleeding was prospectively collected. Questionnaires encompassing multiple aspects of the ease of use and efficacy of PuraStat ${ }^{\circledR}$ were completed by ten surgeons (five consultants and five senior registrars) and analysed to gauge the performance of the product.

Results: No major adverse cardiac events were reported in this cohort. Complications such as atrial fibrillation, pacemaker requirement and pleural effusions were comparable to the national average. Mean blood product use of packed red cells, platelets, fresh-frozen plasma (FFP) and cryoprecipitate was below the national average. There was one incidence of re-exploration, however this was due to pericardial constriction rather than bleeding. Analysis of questionnaire responses revealed that surgeons consistently rated PuraStat ${ }^{\oplus}$ highly (between a score of 7 and 10 in the various subcategories). The transparent nature or PuraStat ${ }^{\oplus}$ allowed unobscured visualisation of suture sites and possessed excellent qualities in terms of adherence to site of application. The application of PuraStat ${ }^{\oplus}$ did not interfere with the use of other haemostatic agents or manipulation of the suture site by the surgeon.
\end{abstract}

Conclusion: PuraStat ${ }^{\oplus}$ is an easy-to-use and effective haemostatic agent in a wide range of cardiac and aortic surgical procedures.

Keywords: Cardiac surgery, Bleeding, Haemostasis, Haemostatic agents, Blood loss, Blood products, Transfusion

\section{Background}

Meticulous haemostasis remains a core principal in surgical practice, both for patient safety and for preserving the integrity of surgical repair [1]. The challenge of cardiac surgery involves operating on patients who are receiving single and dual antiplatelet or anticoagulant therapy, systemic heparinization and the effects of hypothermia on the clotting cascade [2]. The consequences of massive haemorrhage are well recognised and rare in modern practice as bleeding into the

\footnotetext{
*Correspondence: suresh.giritharan@gmail.com

'Wessex Cardiac Centre, University Hospitals Southampton, Tremona Road,

Southampton SO16 6YD, UK

${ }^{2}$ Southampton, UK
}

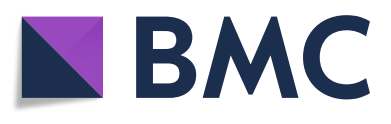

(c) The Author(s). 2018 Open Access This article is distributed under the terms of the Creative Commons Attribution 4.0 International License (http://creativecommons.org/licenses/by/4.0/), which permits unrestricted use, distribution, and reproduction in any medium, provided you give appropriate credit to the original author(s) and the source, provide a link to the Creative Commons license, and indicate if changes were made. The Creative Commons Public Domain Dedication waiver (http://creativecommons.org/publicdomain/zero/1.0/) applies to the data made available in this article, unless otherwise stated. ise by cardiac tamponade.

The search for an ideal haemostatic adjunct to complement suturing of cardiac and aortic tissue and in fashioning anastomoses is ongoing, as the agent must possess a comprehensive catalogue of qualities such as ease of application, good adherence to site of use, cause minimal tissue reaction and prove robust in withstanding volume and pressure changes generated from the beating heart [3]. Currently there are many established haemostatic agents on the market with varying mechanisms of action, which attests to the fact that there is no one ideal agent (Figs. 1 and 2).

In this study we report our experience using PuraStat ${ }^{\circ}$ (3-D Matrix Europe SAS, Caluire et Cuire, France) a 


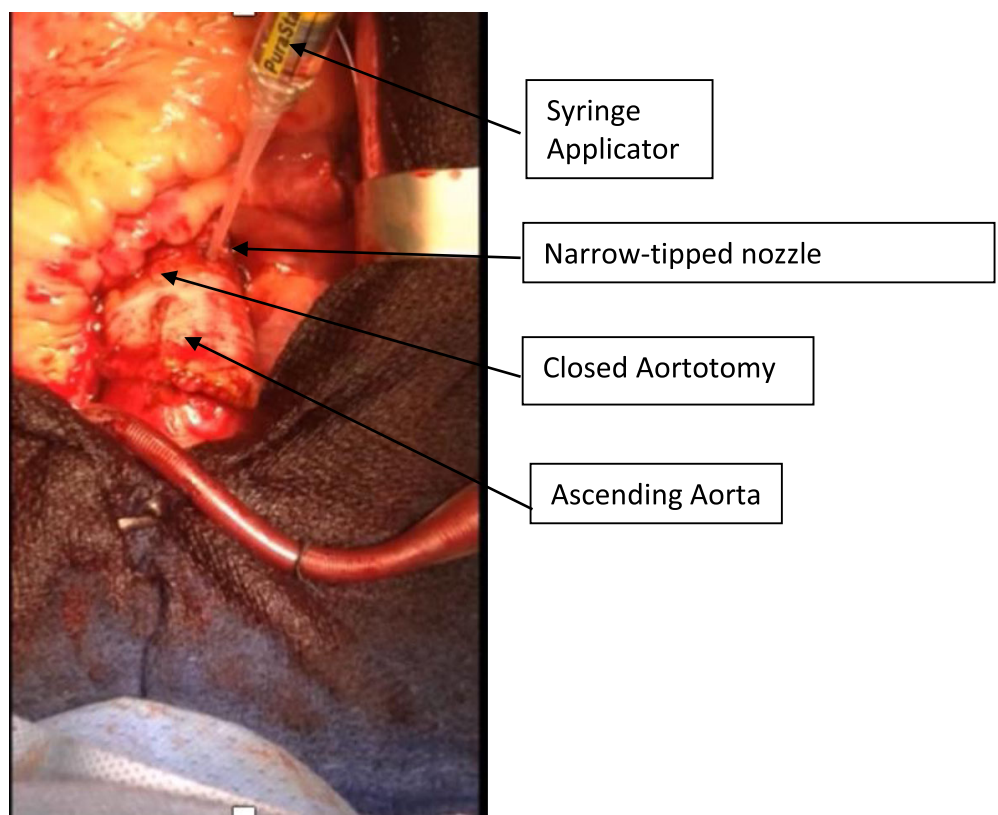

Fig. 1 Application of PuraStat ${ }^{\circledR}$ via syringe applicator with a long, narrow nozzle over aortotomy suture line

novel synthetic haemostat. It relies upon nanotechnology with the self-assembling of constituent peptides, which is triggered by sodium ions within the blood to form a synthetic, non-biogenic, biocompatible, resorbable peptide hydrogel with no risk of transmissible spongiform encephalopathies [4]. It is CE-marked for haemostatic use in humans and is currently being used successfully as a standalone haemostatic agent in endoluminal gastrointestinal procedures, among other applications [5]. Our aim was to investigate the haemostatic efficacy of PuraStat ${ }^{\circ}$ for cardiac and aortic anastomoses and suture lines.

\section{Methods}

A prospective, non-randomised study was conducted at our institution between February 2017 and September 2017. A total of fifty patients undergoing cardiac surgery at the Wessex Cardiothoracic Centre (Southampton,
UK) and The Spire Hospital (Southampton, UK) were recruited. The inclusion criteria encompassed all adult cardiac surgery cases where the intraoperative use of a haemostatic agent was deemed necessary. A comprehensive case-mix including coronary artery bypass surgery, aortic valve surgery, mitral valve surgery, surgery on the thoracic aorta and other concomitant procedures (e.g. atrial fibrillation ablation procedures) were included, encompassing elective, urgent and emergency presentations. Patients whom exhibited preoperative derangements in haematological and coagulation profiles, and baseline derangements in liver function were excluded. Baseline demographic data such as age, gender, BMI, hypertension, diabetes, hypercholesterolaemia, previous myocardial infarction (MI), left ventricular (LV) function, smoking status, asthma or chronic obstructive pulmonary disease (COPD), renal impairment, neurological

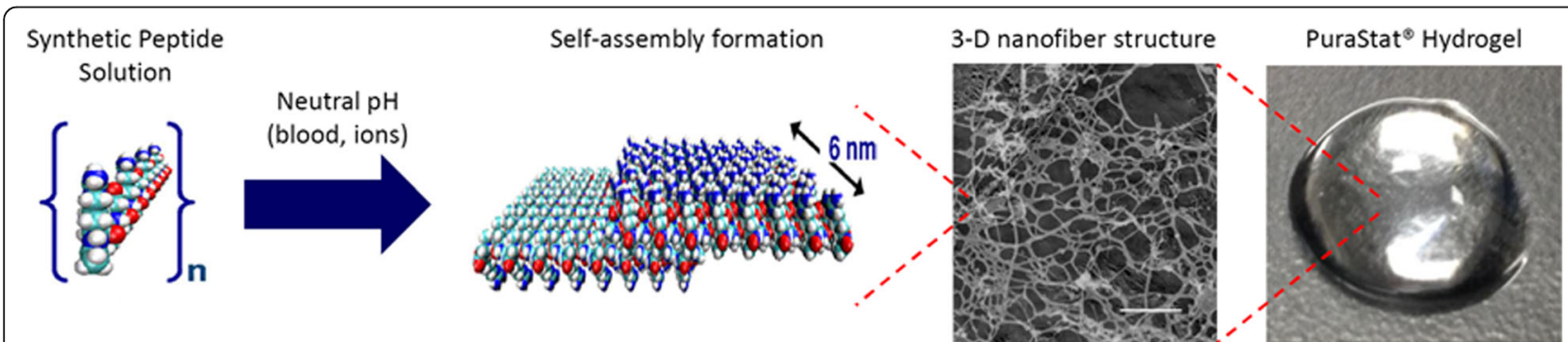

Fig. 2 Contact between PuraStat ${ }^{\oplus}$ and physiological liquid such as blood causes the acidic peptide solution to approach neutral pH and be exposed to ions. This triggers self-assembly of $ß$-sheets and then nano-fibres within a hydrogel. The hydrogel rapidly covers the point of bleeding and provides a physical surface under which coagulation occurs to achieve haemostasis. (figure courtesy of 3-D Matrix) 
impairment and peripheral vascular disease was collected from pre-admission clerking sheets. Additional data included the use of preoperative antiplatelet or anticoagulant therapy. Preoperative blood results for haemoglobin, platelet count, INR, APTR and fibrinogen were also noted.

Intraoperative data included details of the operation, cardiopulmonary bypass time, aortic cross-clamp time and site of use of PuraStat ${ }^{\circ}$ and if additional haemostatic agents were required to achieve haemostasis. In all cases, the application of PuraStat ${ }^{\circ}$ was done following reversal of systemic heparinization with Protamine Sulfate.

As the purpose of this study was to evaluate feasibility and efficacy, a questionnaire was developed with a view of gaining detailed observation and feedback on the use of PuraStat ${ }^{\circ}$ in various scenarios. These questionnaires were given to the operating surgeon to complete following use of the product. The surgeons were asked to score the product on a scale of 1-10 for various factors. These were site of application, grade of bleeding, ease of preparation, time of preparation, ease of delivery to the sterile field, ease of use, delivery to the sterile field, application, conformation to irregular surfaces, compatibility with other haemostatic agents (when used), and reduction in haemostatic time. The questionnaire paid particular emphasis on the efficacy of PuraStat ${ }^{\circ}$ alone in achieving haemostasis, and if not, what other haemostatic agent was used in conjunction with PuraStat ${ }^{\circ}$. Surgeons were also asked about their overall satisfaction with PuraStat ${ }^{\circ}$. A total of ten surgeons (five consultants and five senior registrars) provided feedback.

Chest drain output over the first $24 \mathrm{~h}$ was recorded along with the total use of blood products (packed red blood cells, platelets, fresh frozen plasma (FFP) and cryoprecipitate). Postoperative complications such as death, postoperative myocardial infarction, stroke, re-exploration for bleeding, atrial fibrillation, other arrhythmia, pleural effusion and reintubation were collated from a review of contemporaneously-completed inpatient notes. The results were then tabulated, with categorical variables expressed as a percentage of the total patient population and continuous variables expressed as the mean value with standard deviations. The mean rating for each criterion gauged in the questionnaire was calculated.

\section{Results}

\section{Baseline demographics}

Within the seven-month period, a total of fifty patients were recruited, and their baseline demographics are displayed below (Table 1 ) The mean age was $71.9 \pm 10.4$ years and the mean body mass index (BMI) was $28.7 \pm 4.8 \mathrm{~kg} /$ $\mathrm{m}^{2}$. Thirty $(60 \%)$ of participants were male and twenty (40\%) were female. In terms of preoperative comorbidities, twenty-eight (56\%) had hypertension (defined as patients
Table 1 Baseline Demographics of Patients

\begin{tabular}{|c|c|c|c|}
\hline Variable & number (\% of total) & mean & SD \\
\hline Age & & 71.9 & 10.4 \\
\hline \multicolumn{4}{|l|}{ Gender } \\
\hline Male & $30(60 \%)$ & & \\
\hline Female & $20(40 \%)$ & & \\
\hline $\mathrm{BMI}\left(\mathrm{kg} / \mathrm{m}^{2}\right)$ & & 28.7 & 4.8 \\
\hline Hypertension & $28(56 \%)$ & & \\
\hline Diabetes & $11(22 \%)$ & & \\
\hline Myocardial Infarction? & $5(10 \%)$ & & \\
\hline Asthma/COPD & $3(6 \%)$ & & \\
\hline Peripheral Vascular Disease & $5(10 \%)$ & & \\
\hline Never smoked & $36(72 \%)$ & & \\
\hline \multicolumn{4}{|l|}{ Left Ventricular Function } \\
\hline Good & $45(90 \%)$ & & \\
\hline Moderate & $4(8 \%)$ & & \\
\hline Poor & $1(2 \%)$ & & \\
\hline \multicolumn{4}{|l|}{ Preoperative Blood Results } \\
\hline Haemoglobin & & 130.5 & 14.3 \\
\hline Platelets & & 240.2 & 71.6 \\
\hline INR & & 1.06 & 0.12 \\
\hline APTR & & 1.05 & 0.2 \\
\hline Fibrinogen & & 4.54 & 1.18 \\
\hline
\end{tabular}

Values are total number of patients, $\mathrm{n}(\%$ of $\mathrm{n})$, mean and standard deviation (SD). BMI, body mass index; MI, myocardial infarction; COPD, chronic obstructive pulmonary disease; INR, international normalized ratio; APTR, activated partial thromboplastin time ratio

receiving antihypertensive medications or having known but untreated hypertension [blood pressure $>140$ / $90 \mathrm{mmHg}]$ ), eleven patients (22\%) had diabetes (fasting glucose $>7 \mathrm{mmol} / \mathrm{L}$ ), five patients had preoperative myocardial infarction (10\%), three patients $(6 \%)$ had chronic obstructive pulmonary disease (COPD) and four patients (8\%) had peripheral vascular disease (PVD). Thirty-six (72\%) of the participants had never smoked.

All patients in this cohort underwent preoperative transthoracic echocardiographic examination. Forty-five (90\%) of patients had good left ventricular function, four patients (8\%) had moderate left ventricular function and one patient $(2 \%)$ had poor left ventricular function. Blood results taken prior to surgery demonstrated mean values for haemoglobin level $(130.5 \pm 14.3 \mathrm{~g} / \mathrm{dL})$, platelet count $(240.2 \pm 71.6 \times 10 \mathrm{e} 9 / \mathrm{L})$, INR $(1.05 \pm 0.12)$, APTR $(1.05 \pm 0.2)$ and fibrinogen $(4.54 \pm 1.18 \mathrm{~g} / \mathrm{L})$.

\section{Type of operation and site of use}

Figures 3 and 4 illustrate the type of operations performed as well as the site of PuraStat ${ }^{\circ}$ use. In all cases, the application of PuraStat ${ }^{\circ}$ was done following reversal of systemic heparinization with Protamine Sulfate. 


\section{Type of Operation}

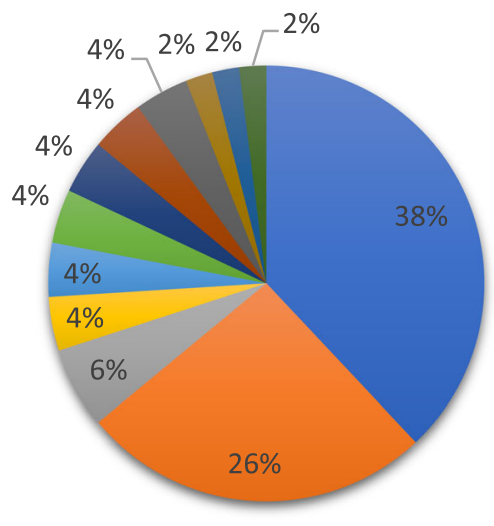

\begin{tabular}{|c|c|c|c|}
\hline aVR & AVR + CABG & Asc Ao Replacement & CABG \\
\hline aVR + IP Graft & MV Repair & David Procedure & 匹 Redo AVR \\
\hline
\end{tabular}

Fig. 3 Type of Operation. AVR, aortic valve replacement; MV, mitral valve; CABG, coronary artery bypass grafts; Asc Ao, Ascending Aorta

Thirty eight percent of patients underwent aortic valve replacement, 26\% underwent aortic valve replacement and concomitant coronary artery bypass surgery and $6 \%$ of patients had replacement of the ascending aorta with a prosthetic graft. Four percent of patients each had aortic valve replacement with concomitant interpositional graft placement, isolated coronary artery bypass graft surgery, mitral valve repair, valve-sparing aortic root replacement (David Procedure), redo aortic valve replacement and aortic root replacement. Two percent of patients each had emergency repair of a Type A dissection, concurrent aortic and mitral valve replacement and aortic hemiarch replacement with a Thoraflex graft. PuraStat ${ }^{\circ}$ was most frequently used at the site of aortotomy closure (62\%), followed by haemostasis of graft suture lines (18\%). It was used to aid haemostasis on closure of the site in $6 \%$ of cases, and for $4 \%$ of cases each was applied to aortic and right atrial cannulation sites, to needle hole bleeds from prosthetic grafts and to the top ends of vein grafts during CABG surgery. In one

\section{Site of PuraStat ${ }^{\circledR}$ Application}
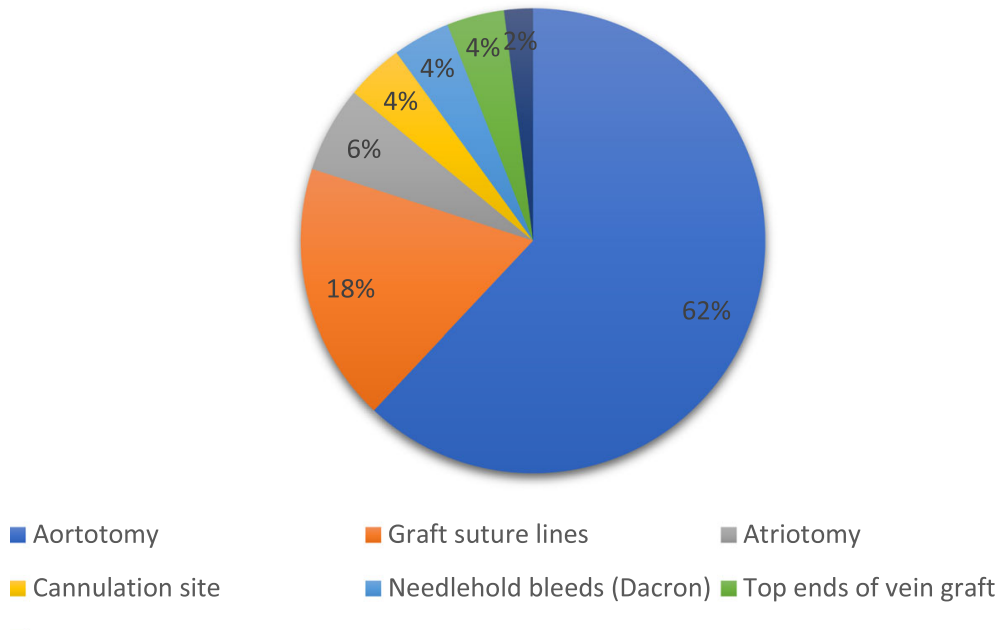

- Patch repair to aortic root

Fig. 4 Site of Use of PuraStat ${ }^{\oplus}$ 
case $(2 \%)$ it was used to aid the fashioning of a pericardial patch which was implanted onto the aortic root.

\section{Total blood product use and 24-h blood lost via intercostal drain output}

Table 2 details the mean number of units for blood products such as packed red blood cells (blood), platelets, fresh frozen plasma (FFP) and cryoprecipitate. Additionally, the average number of units of Prothrombin Complex Concentrate $\left(\right.$ Octaplex $\left.^{\circ}\right)$ is included. These results were compared to those of the 2011 Audit of Blood Transfusion in Adult Cardiac Surgery (National Comparative Audit of Blood Transfusion) [6]. Mean values for units of packed redcells $(1.45 \pm 1.99)$, platelets $(1.22$ $\pm 1.07)$, fresh frozen plasma $(0.94 \pm 1.36)$ and cryoprecipitate $(1.33 \pm 1.73)$ were lower than the national average. Mean units of Octaplex use was $1.19 \pm 1.54$. The percentage reduction of use of blood products in this cohort as compared to the national average was $51.34 \%$ for packed red cells, $34.05 \%$ for platelets, $52.5 \%$ for fresh-frozen plasma and $16.35 \%$ for cryoprecipitate.

Table 3 highlights the mean blood loss via intercostal drain output for the first $24 \mathrm{~h}$ following surgery and the total cell-salvaged volume transfused following surgery. All patients were infused with the total volume of cell-salvaged blood from cardiopulmonary bypass within the first $24 \mathrm{~h}$ following surgery.

\section{Questionnaire results}

Table 4 lists the mean scores given by ten surgeons on their experience when using PuraStat ${ }^{\circ}$. Every surgeon surveyed has had considerable experience performing the operations in which they used the product, has had the opportunity to use the product more than once and has had experience using similar products from other manufacturers. All theatre scrub staff received training on the product prior to use. PuraStat ${ }^{\circ}$ scored very highly on pre-application factors such as preparation of the product and dispensation from the applicator. A mean score of 9.7 was assigned for ease of application to the target site. Scores of 8.5, 8.3 and 8.9 respectively were assigned for application to hard-to-reach surfaces, conformation to irregular surfaces and ease of removal (of excess material) from the surgical field. Surgeons found PuraStat ${ }^{\circ}$ worked well with other agents, reporting no issues such as smudging, sticking or impaired adherence to the target site when used with Fibrillar (classified as a haemostat) or BioGlue (classified as a sealant/glue). It was thought to be valuable in reducing haemostasis time (mean score $=7.5$ ), and subsequently operating time (mean score $=7.3$ ), and in $84 \%$ of the cases was adequate in achieving haemostasis without the aid of other haemostatic agents ( $8 \%$ used concurrently with Fibrillar ${ }^{\circ}$, $6 \%$ used with both Fibrillar ${ }^{\ominus}$ and BioGlue ${ }^{\circ}$ and $2 \%$ used concurrently with BioGlue ${ }^{\circ}$.

\section{Postoperative complications}

Table 5 lists the inpatient postoperative complications for this cohort of patients. No deaths, cerebrovascular accidents (CVA) or myocardial infarctions (MI) were reported. Fourteen patients (28\%) experienced new postoperative atrial fibrillation while ten patients $(20 \%)$ had pleural effusions confirmed on a chest radiograph. None of the patients were re-explored for bleeding; one patient required surgical re-exploration due to a presentation mimicking cardiac tamponade, however this turned out to be pericardial constriction causing a low cardiac output status. No bleeding was reported from this event.

\section{Discussion}

A major challenge when confronted with small-volume, persistent oozing from vascular structures is the limited role of suturing, as every additional bite taken will result in more needle-hole bleeding points. The aforementioned insults to the intrinsic physiological clotting mechanisms from antiplatelet therapy, systemic heparinization and cooling further exacerbate this problem [7, 8]. The current selection of topical haemostatic agents on the market have demonstrated satisfactory haemostatic properties, but has the potential pitfall of enabling transmission of viral and prion diseases (in the case of human blood component-derived substances), and instigating a systemic inflammatory response syndrome to animal-derived peptide-based products $[9,10]$. The risk of such complications is negated by the use of a completely synthetic agent like PuraStat ${ }^{\circ}$.

In this consecutive case series surgeons reported several distinct qualities of PuraStat ${ }^{\bullet}$ which were felt to be advantageous. The transparent nature provided surgeons

Table 2 Total blood product use compared to the national average

\begin{tabular}{lllll}
\hline Blood Products Used & Mean units, $\mathrm{n}$ & SD & UK Average (CABG) & reduction (\%) \\
\hline Packed Red Cells & 1.45 & 1.99 & 2.98 & $51.34 \%$ \\
Platelets & 1.22 & 1.07 & 1.85 & $34.05 \%$ \\
FFP & 0.94 & 1.36 & 1.98 & $52.50 \%$ \\
Cryoprecipitate & 1.33 & 1.73 & 1.59 & $16.35 \%$ \\
Octaplex & 1.19 & 1.54 & n/a & n/a \\
\hline
\end{tabular}


Table 3 Mean cell-salvaged blood infused and 24-h chest drain output

\begin{tabular}{lll}
\hline $\begin{array}{l}\text { Cell-salvaged blood and } \\
\text { Chest Drain Output }\end{array}$ & $\begin{array}{l}\text { Mean Volume, } \\
\mathrm{ml}\end{array}$ & SD \\
\hline Cell-salvaged blood infused & 668.73 & 280.8 \\
Chest Drain output $(24 \mathrm{~h})$ & 362.07 & 287.06 \\
\hline
\end{tabular}

with the novel opportunity to maintain visualisation of the suture line after application of the haemostat. This allowed the opportunity for surveillance of the operative field for slow accumulation of haematoma sandwiched between the vessel and the haemostat layer during the course of the remainder of the operation. A threatened or suboptimal suture repair can then be revised if needed, potentially preventing the need for postoperative re-exploration. The method of delivery and application as a viscous gel rather than a spray applicator was an essential feature when operating within a tight surgical field, enhancing precision (i.e. application over the aortotomy with multiple vein grafts invading the field of view).

The viscosity profile of PuraStat ${ }^{\ominus}$ which demonstrates a more cohesive rather than adhesive characteristic, makes it ideal for concomitant use with other haemostatic materials (in this case, BioGlue $e^{\circ}$ and Fibrillar ${ }^{\circ}$ ). Cross-compatibility with such products is essential, especially in complex aortic procedures in which deep hypothermic circulatory arrest (DHCA) is utilised as the

Table 4 Mean user evaluation scores on the feasibility and efficacy of PuraStat ${ }^{\oplus}$

\begin{tabular}{|c|c|}
\hline Surgeons' Rating of PuraStat ${ }^{\oplus}$ & Average score (1-10) \\
\hline $\begin{array}{l}\text { Ease and efficiency of preparation } \\
\text { prior to use }\end{array}$ & 10 \\
\hline Easy to dispense from applicator & 10 \\
\hline Ease of application to site of bleed & 9.7 \\
\hline Application to hard-to-reach surfaces & 8.5 \\
\hline Conformation to irregular surfaces & 8.3 \\
\hline $\begin{array}{l}\text { Ease of removal of excess PuraStat }{ }^{\oplus} \\
\text { from field }\end{array}$ & 8.9 \\
\hline $\begin{array}{l}\text { Concomitant use with other } \\
\text { haemostatic agents }\end{array}$ & 9.4 \\
\hline $\begin{array}{l}\text { Valuable in reducing haemostasis } \\
\text { time? }\end{array}$ & 7.5 \\
\hline $\begin{array}{l}\text { Potential in reduction of operating } \\
\text { time? }\end{array}$ & 7.3 \\
\hline \multirow[t]{2}{*}{ PuraStat ${ }^{\oplus}$ alone enough to achieve haemostasis? } & $\mathrm{YES}=\mathbf{8 4} \%$ \\
\hline & $\mathrm{No}=16 \%$ \\
\hline \multirow[t]{4}{*}{ Other products used concomitantly } & None $=84 \%$ \\
\hline & Fibrillar $^{\oplus}=8 \%$ \\
\hline & $\begin{array}{l}\text { BioGlue + Floseal } \\
=6 \%\end{array}$ \\
\hline & BioGlue $=2 \%$ \\
\hline
\end{tabular}

Table 5 Postoperative Complications

\begin{tabular}{ll}
\hline Postoperative Complications & Number \\
\hline AF & $14(28 \%)$ \\
Pleural effusion & $10(20 \%)$ \\
CVA & 0 \\
Re-exploration for bleeding & 0 \\
Ml & 0 \\
Other arrhythmias & 3 \\
Death & 0 \\
\hline
\end{tabular}

dysregulation of coagulative mechanisms is even more pronounced.

\section{Limitations}

Our primary aim in this study was to determine feasibility of PuraStat ${ }^{\circ}$ in aiding haemostasis in cardiac surgery. By evaluating the use this product in fifty consecutive cases, we have established that in a wide variety of surgical scenarios, PuraStat ${ }^{\circ}$ is shown to be effective in achieving haemostasis. Patients in this study were not stratified according to preoperative risk factors for general morbidity and mortality from cardiac surgery. Neither were they stratified for their individual risks of bleeding and poor tissue healing (i.e. preoperative antiplatelet therapy, type 2 diabetes, corticosteroid use, congestive heart failure and chronic renal failure). The type, length and urgency of the operation would also influence major adverse cardiac events and postoperative bleeding. We propose a follow-up study where patients are propensity-score matched for these criteria [11].

The variation of surgical practice and experience between the ten surgeons resulted in variations in the strategy of application of PuraStat ${ }^{\circ}$ (i.e. precise location of application and quantity) as well as judgement on how quickly haemostasis was achieved. The point at which different surgeons deemed the product insufficient for haemostasis (and subsequently a different product or change in operative strategy was employed) was not recorded. Previous trials of the efficacy of haemostatic agents have assessed efficacy by standardising the anatomical point of use and time window in achieving bleeding control. Such stringent criteria would provide valuable objective, quantitative data.

\section{Conclusion}

Our single-centre, qualitative evaluation found PuraStat ${ }^{\circ}$ to be a feasible, safe and effective haemostatic agent in a wide range of cardiac and aortic surgical procedures. Specific qualities in terms of the transparent nature and viscosity profile of the product was found to be novel and valuable in our surgical practice. A further 
randomised-controlled study where patients are propensity-matched for baseline demographics, operative urgency, bleeding risk, tissue integrity factors and operation type is warranted to quantitatively evaluate the performance of PuraStat $^{\oplus}$ in various specific circumstances.

\section{Abbreviations}

AF: Atrial Fibrillation; Ao Root: Aortic Root; APTR: Activated Partial Thromboplastin Time Ratio; Asc Ao: Ascending Aorta; AVR: Aortic Valve Replacement; BMI: Body Mass Index; CABG: Coronary Artery Bypass Graft; COPD: Chronic Obstructive Pulmonary Disease; CVA: Cerebrovascular Accident: DHCA: Deep Hypothermic Circulatory Arrest; FFP: Fresh Frozen Plasma; INR: International Normalised Ratio; IP: Interposition; LV: Left Ventricle; Ml: Myocardial Infarction; MV: Mitral Valve; MVR: Mitral Valve Replacement; PVD: Peripheral Vascular Disease; RA: Right Atrium

\section{Acknowledgements}

We would like to thank Consultant Surgeons (Mr Clifford Barlow, Mr. Geoffrey Tsang, Mr. Theodore Velissaris and Mr. Szabolcs Miskolczi), Senior Surgical Fellows (Mr Syed Sadeque and Mr. Hassan Kattach) and Specialist Registrars (Mr Mano Navaratnarajah, Mr. Simon Duggan and Mr. Aiman Alassar) for completing the questionnaires.

\section{Availability of data and supporting materials}

Please contact author Suresh Giritharan (email: suresh.giritharan@gmail.com) for data requests.

\section{Funding}

This research received no specific grant from any funding agency in the public, commercial, or not-for-profit sectors.

\section{Author's contributions}

Sunil Ohri and Geoffrey Tsang were responsible for the conceptualization of the study and reviewing the final manuscript. Kareem Salhiyyah was responsible for designing the data capture proforma. Geoffrey Tsang was responsible for access to blood transfusion data and final critical revision of the data. Suresh Giritharan was responsible for data collection, analysis and preparation the manuscript.

\section{Competing interests}

Sunil Ohri has received speaker's fees from 3-D Matrix Europe SAS, Caluire et Cuire, France. Suresh Giritharan and Kareem Salhiyyah and Geoffrey Tsang have no declarations.

\section{Ethics approval and consent to participate}

Not Applicable, as this is an opportunistic, retrospective review of a product that has already attained a CE-mark to be used routinely in a surgical setting.

\section{Publisher's Note}

Springer Nature remains neutral with regard to jurisdictional claims in published maps and institutional affiliations.

Received: 28 January 2018 Accepted: 31 May 2018

Published online: 15 June 2018

\section{References}

1. Levi $M$, Cromheecke $M E$, de Jong $E$, Prins $M H$, de Mol BJM, Briët $E$, et al. Pharmacological strategies to decrease excessive blood loss in cardiac surgery: a meta-analysis of clinically relevant endpoints. Lancet. 1999;354:1940-7.

2. $\mathrm{Oz} \mathrm{MC}$, et al. Controlled clinical trial of a novel hemostatic agent in cardiac surgery. Ann Thorac Surg. 2000;69:1376-62.

3. Masuhara H, MD FT, Watanabe T, Koyama N, Tokuhiro K. Novel infectious agent-free hemostatic material (TDM-621) in cardiovascular surgery. Ann Thorac Cardiovasc Surg. 2012;18:444-51.

4. Shander A, Kaplan L, Harris M, Gross I, Nagarsheth N, Nemeth J, et al. Topicral hemostatic therapy in surgery: bridging the knowledge and practice gap. J Am Coll Surg. 2014;219:570-9.
5. Subramaniam S, Kandiah K, Thayalasekaran S, Longcroft-Wheaton G, Bhandari P. Bleeding during endoscopic resection: a novel extracellular scaffold matrix is a safe and effective haemostatic agent. Gut. 2017;66:214-5.

6. Murphy M, Murphy G, Gill R, Herbertson M, Allard S, Grant-Casey J. 2011 Audit of Blood Transfus in Adult Cardiac Surgery Oxford: NHS Blood and Transplant, National Comparitive Audit of Blood Transfusion; 2011.

7. Hartmann M, Sucker C, Boehm O, Koch A, Loer S, Zacharowski K. Effects of cardiac surgery on hemostasis. Transfus Med Rev. 2006;20:230-41.

8. Nasso G, Piancone F, Bonifazi R, Romano V, Visicchio G, De Filippo C, et al. Prospective, randomized clinical trial of the FloSeal matrix sealant in cardiac surgery. Ann Thorac Surg. 2009;88:1520-6.

9. Despotis G, Avidan M, Eby C. Prediction and Bleeding Management in Cardiac Surgery. J Thromb Haemost. 2009;7:111-7.

10. Ibrahim M, Aps C, Young C. A foreign body reaction to Surgicel mimicking an abcess following cardiac surgery. Eur J Cardiothorac Surg. 2002;22:489-90.

11. Ortel T, Mercer M, Thames E, Moore K, Lawson J. Immunologic Impact and Clinical outcomes after surgical exposure to bovine thrombin. Ann Surg. 2001;233:88-96.

\section{Ready to submit your research? Choose BMC and benefit from:}

- fast, convenient online submission

- thorough peer review by experienced researchers in your field

- rapid publication on acceptance

- support for research data, including large and complex data types

- gold Open Access which fosters wider collaboration and increased citations

- maximum visibility for your research: over $100 \mathrm{M}$ website views per year

At BMC, research is always in progress.

Learn more biomedcentral.com/submissions 